\title{
Research Paper: Health-Related Quality of Life of Mothers of Children With Intellectual Disability
}

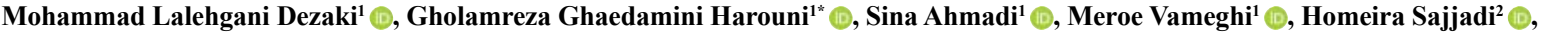 \\ Mansoore Ghafari ${ }^{1}$
}

1. Social Welfare Management Research Center, University of Social Welfare and Rehabilitation Sciences, Tehran, Iran. 2. Social Determinants of Health Research Center, University of Social Welfare and Rehabilitation Sciences, Tehran, Iran

\begin{tabular}{|l|l|l}
$\begin{array}{c}\text { use your device to scan } \\
\text { and read the article online }\end{array}$ & $\begin{array}{l}\text { Cttation Lalehgani Dezaki M, Ghaedamini Harouni Gh, Ahmadi S, Vameghi M, Sajjadi H, Ghafari M. Health-Related Qual- } \\
\text { ity of Life of Mothers of Children With Intellectual Disability. Iranian Rehabilitation Journal. 2018; 16(4):361-370. http://dx.doi. } \\
\text { org/10.32598/irj.16.4.361 }\end{array}$ \\
doi http://dx.doi.org/10.32598/irj.16.4.361
\end{tabular}

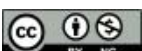

Article info:

Received: 09 Jan 2018

Accepted: 23 Jun 2018

Available Online: 01 Dec 2018

\section{Keywords:}

Social rehabilitation team, Mothers' health-related quality of life, Children with intellectual disability, Burden of care

\section{ABSTRACT}

Objectives: Disability occurs as a sudden and unexpected incident, and coping with it depends on the conditions and lifestyle, the remaining abilities, cooperation of other family members, and the role of rehabilitation team. Rehabilitation work includes medical, professional and social rehabilitation teams. The family is also defined as an essential member of the social rehabilitation team. The present study aimed to assess the quality of life of mothers of children with intellectual disabilities, as an important member of the social rehabilitation team.

Methods: In this analytical and descriptive study, statistical population consisted of all Mothers of Mentally Retarded Children (MMRC) (educable, trainable and isolated), and Mothers of Children with Normal Intelligence (MCNI) in Shahr-e-Kord City, Iran. Total sample size was considered to be 306. For gathering data, the 36-Item Short Form Health Survey instrument, validated in Iran, and for analyzing the data 1-way ANOVA, linear regression and discriminant analysis were used.

Results: In terms of all quality of life dimensions and total score, there was a significant difference between the two groups $(\mathrm{P}<0.001)$ and $\mathrm{MCNI}$ group scored higher compared to MMRC group. The greatest difference between the two groups was related to physical function (effect size $=40.7 \%$ ), and the least was related to limitations in usual role activities because of emotional problems (effect size $=30.9 \%$ ).

Discussion: Mothers are an important mediator in providing rehabilitation services (secondary or tertiary prevention) to their children. Once their roles are neglected in the rehabilitation team work, the secondary and tertiary prevention activities for the disabled child will not be effective, and in the near future, mothers will be among the most vulnerable groups requiring rehabilitation services. Therefore, during the provision of secondary and tertiary prevention services for children, mothers' health status should also be monitored for the purpose of primary prevention.

* Corresponding Author:

Gholamreza Ghaedamini Harouni, PhD.

Address: Social Welfare Management Research Center, University of Social Welfare and Rehabilitation Sciences, Tehran, Iran.

Tel: +98 (913) 7026950

E-mail: qaedamini@gmail.com 


\section{Highlights}

- The quality of life in $46.8 \%$ of mothers of children with intellectual disabilities was low.

- About $96.5 \%$ of mothers of healthy children described their quality of life as moderate to high and only $3.5 \%$ of them had a poor quality of life.

- The quality of life of mothers with healthy children was higher in all 8 dimensions compared to mothers of children with intellectual disabilities.

\section{Plain Language Summary}

According to our survey, $46.8 \%$ of mothers of children with intellectual disabilities complained of their low quality of life. On the contrary, $96.5 \%$ of mothers of healthy children described their quality of life as moderate or high and only $3.5 \%$ of them reported a poor quality of life. The quality of life of mothers with healthy children was higher in all 8 studied dimensions compared to mothers of children with intellectual disabilities.

\section{Introduction}

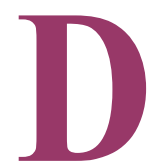

isability usually occurs suddenly and unexpectedly as an undesired incident [1]. According to the World Health Organization statistics, a disabled child is born every 8 minutes in the world [2]. Three to 7 children per 1000 are born with Intellectual Disability (ID) [3]. In developing countries, 10 to $15 \%$ of people are affected with disabilities [4], from which, 1 to $3 \%$ suffer from ID. ID refers to individuals with an IQ of less than 70 with impaired adaptive functions that has been occurred before the age of 18 years [5]. In Iran, a massive amount of more than 1.5 million people suffer from disabilities. Three percent of these people have severe disability, and according to the 2006-2011 censuses, ID accounts for the highest rate of disabilities [6].

Coping with this crisis depends on personal characteristics, lifestyle type, remaining abilities, cooperation of family members, and the role of rehabilitation team [1]. Parents, among family members, are the principle models of understanding and acceptance for the disabled person. Therefore, parents' response to their children's mental retardation plays a vital role in creating a favorable atmosphere for the disabled child and other family members [7]. Parents' reactions to their child's condition also vary according to their personality characteristics, time, and so on [7]. One of the most important determinants in this regard is the Quality of Life (QoL) of mothers, as the main caregivers of the disabled children [8].
In recent years, QoL, and in particular, the healthrelated QoL, has been significantly considered as an important indicator in assessing people's well-being $[9,10]$. The QoL is the people's perception and understanding of their position in relation to their goals and values according to the objective living conditions [3]. While QoL includes many aspects, health-related QoL is mainly related to biopsychological health [11] and expresses the functional effects of illness and its outcomes on people's perceptions.

The QoL is affected by different living conditions of people at individual, family and social levels [12]. One of these stressful situations is the birth or presence of a disabled child; particularly a child with ID in the family [13]. Caring for children with a disability with specific physical, emotional and social needs often affects family functions and is associated with many emotional and behavioral problems for parents and especially mothers [14-16]. A disabled child refers to a child with a mental or physical disorder or a combination of both [17]. Such children might be considered disable by the community due to their appearance or behavior and functional/activity limitations, or be formally identified as such [18].

Studies suggest that biopsychological health and consequently the QoL of mothers with disabled children are significantly lower than those with healthy children [19-23]. Moreover, parents of children with ID appear to tolerate more stress and anxiety than other parents $[5,24]$. Such stress and anxiety may be related to their children's future problems, disability costs, people's 
impressions and attitudes towards the children, parent's wishes, etc. that greatly affect the parents' QoL.

In Iran, a number of studies also identified a difference between the QoL of mothers with disabled children and mothers of healthy children [25-27]. This also applies to mothers of children with ID [28]. Children with ID have more needs than other healthy children $[5,13,24]$; they impose more emotional and economic burden on parents [6], and their mothers are often the ones to bear the most burden, because of their close relationship with their children. Thus, they tend to endure more problems than other mothers.

In the rehabilitation services (secondary and tertiary prevention levels) aimed at disabled people, teams of medical rehabilitation, professional rehabilitation and social rehabilitation, work together and the disable person's family is also part of the social rehabilitation team [1]. Investigating QoL is important in parents with disabled children [29]. The concept of QoL depends on the socio-cultural context. The number of disabled people is growing in Iran. There are limited studies on the QoL of mothers of children with ID. Thus, this study was conducted to evaluate the QoL of mothers of children with ID in Shahr-e-kord City, Iran.

\section{Methods}

This descriptive and analytical study was conducted in Shahr-e-kord City, Chaharmahal and Bakhtiari Province from October 2015 to June 2016. Samples included 2 groups of mothers. Group A) Mothers of Mentally Retarded Children (MMRC) including educable intellectually disabled with an IQ of 50 to 70, trainable children with an IQ of 25 to 50, and isolated children with an IQ of $>25$ [30]. According to State Welfare Organization of Chaharmahal and Bakhtiari, the number of children with ID has been 1125 persons since 2016 . Group B) Mothers of Children with Normal Intelligence (MCNI).

Based on a moderate effect size of 0.3 , a statistical power of 0.80 , alpha of 0.05 , equal proportion of 2 groups of mothers, as well as considering an additional $10 \%$ samples in each group, the final sample size was considered to be 306 people. Mothers having children of under 18 years of age in group A were selected by convenience sampling method from Nikan comprehensive rehabilitation center, Mehregan comprehensive center and Bording center of Ferdows for caring of intellectually disabled children. Mothers of children below 18 years of age in group B were selected by ran- dom sampling method. The samples of group B were assessed at their place of residence.

Mothers' QoL was measured by the 36-item Short Form Health Survey (SF-36). Its validity and reliability have been confirmed on the Iranian population by Montazeri and colleagues [31]. The SF-36 contains 36 questions that are used to compute scores on 8 components. Its components include physical functioning, role limitation because of physical health problems, bodily pain, general health, vitality, social functioning, role limitation due to emotional health problems, and mental health. Its scores range between 0 and 100, with a higher score representing a better health related QoL [31].

In the current study, the Cronbach alpha coefficients of all dimensions were $\geq 0.735$. Subjects completed the study tools with an informed consent and full knowledge of the research objectives. The obtained data were analyzed by 1-way Analysis of Variance (ANOVA), multiple linear regression and discriminant analysis in SPSS.

\section{Results}

The Mean \pm SD age of mothers of educable, trainable, isolated children and normal children were $42 \pm 1.56$, $46.7 \pm 1.65,44.5 \pm 1.58$ and $35.9 \pm 0.89$ years, respectively (ANOVA results: $\mathrm{F}[3,294]=18.03, \mathrm{P}<0.001$ ). Mothers and their spouse's educational level, as well as Socioeconomic Status (SES) of the family with respect to the children's condition are presented in Table 1. The ChiSquare Test results revealed a significant relationship between the 3 variables and the child's condition (Table 1).

Initially, we estimated adjusted scores for each dimension and the total index of QoL by 4 predictive variables (i.e. mothers' age, educational level of mothers and spouses and SES) in a multiple linear regression model (Formula 1). Then, we compared the QoL status among the 4 groups of mothers. ANOVA results are presented in (Tables 2 and 3.

Formula (1): Adjusted score $=$ Constant $-\beta_{1}($ age $)+\beta_{2}$ (Mother's educational level) $+\beta_{3}$ (Spouse's educational level) $+\beta_{4}(S E S)$.

According to between-groups 1-way ANOVA results, there was a statistically significant difference at $\mathrm{P}<0.05$ in all dimensions and in the total score of QoL for the 4 groups of mothers (Tables 2 and 3). Post-hoc comparisons using Tukey's HSD (Honestly Significant Difference) Test indicated that the mean score of mothers of normal children was statistically different from the 
Table 1. Sociodemographic characteristics of the studied samples

\begin{tabular}{|c|c|c|c|c|c|c|c|}
\hline Factors & Group & MA and Higher & $\begin{array}{l}\text { Associate } \\
\text { Degree }\end{array}$ & Diploma & $\begin{array}{c}\text { Secondary } \\
\text { School Degree }\end{array}$ & $\begin{array}{l}\text { Elementary } \\
\text { School Degree }\end{array}$ & Illiterate \\
\hline \multirow{5}{*}{$\begin{array}{l}\text { Mother's educa- } \\
\text { tional level (\%) }\end{array}$} & $\begin{array}{c}\text { Educable } \\
(n=50)\end{array}$ & 8 & 4 & 12 & 22 & 26 & 28 \\
\hline & $\begin{array}{c}\text { Trainable } \\
(n=50)\end{array}$ & 6.1 & 4.1 & 2 & 14.3 & 10.2 & 63.3 \\
\hline & $\begin{array}{l}\text { Isolated } \\
(\mathrm{n}=50)\end{array}$ & 14 & 6 & 14 & 10 & 18 & 38 \\
\hline & $\begin{array}{l}\text { Normal } \\
(n=150)\end{array}$ & 41.5 & 20.4 & 22.4 & 6.1 & 6.8 & 2.7 \\
\hline & \multicolumn{7}{|c|}{$x^{2}(18)=129.1, P<0.001$, Cramer's $V=0.387$} \\
\hline \multirow{5}{*}{$\begin{array}{l}\text { Father's educa- } \\
\text { tional level (\%) }\end{array}$} & $\begin{array}{c}\text { Educable } \\
(n=50)\end{array}$ & 14.6 & 4.2 & 20.8 & 10.4 & 25 & 25 \\
\hline & $\begin{array}{c}\text { Trainable } \\
(n=50)\end{array}$ & 19.1 & 2.1 & 21.3 & 2.1 & 14.9 & 40.4 \\
\hline & $\begin{array}{l}\text { Isolated } \\
(\mathrm{n}=50)\end{array}$ & 4.2 & 8.3 & 14.6 & 22.9 & 4.2 & 45.8 \\
\hline & $\begin{array}{l}\text { Normal } \\
(n=150)\end{array}$ & 38.2 & 22.2 & 27.8 & 6.3 & 2.1 & 3.5 \\
\hline & \multicolumn{7}{|c|}{$x^{2}(15)=125.9, P<0.001$, Cramer's $V=0.383$} \\
\hline Factors & Groups & Ver & High & High & Middle & Low & Very Low \\
\hline \multirow{4}{*}{$\begin{array}{l}\text { Socioeconomic } \\
\text { status (\%) }\end{array}$} & Educable $(n=50)$ & & ) & 14 & 40 & 30 & 16 \\
\hline & Trainable $(n=50)$ & & 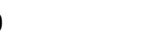 & 8 & 54 & 28 & 10 \\
\hline & Isolated $(n=50)$ & & ; & 16 & 34 & 18 & 26 \\
\hline & Normal $(n=150)$ & & ; & 34 & 51.3 & 7.3 & 1.3 \\
\hline
\end{tabular}

The numbers in the cells are in percentage.

other 3 groups. There was no significant differences among 3 groups of mothers of children with ID. As a result, four groups of mothers were divided into 2 homogeneous groups as follows: A. MMRC; B. MCNI. According to eta-squared (as an effect size measure), the greatest difference between group $\mathrm{A}$ and $\mathrm{B}$ related to "physical functioning" (eta-squared $=40.7 \%$ ) and the least to "role limitations due to emotional problems" (eta-squared $=30.9 \%$ ). A discriminant analysis was used to simultaneously examine the differences between two groups based on 8 dimensions of QoL. Results indicated that about $39 \%$ of difference between the two groups could attribute to the 8 dimensions of QoL.

The mothers'QoL status, which was computed by quartiles $\left(25^{\text {th }}, 50^{\text {th }}\right.$, and $75^{\text {th }}$ percentiles $)$, are presented in Table 4. Based on SF-36, the higher the person's score, the better the QoL status. Therefore, the $25^{\text {th }}$ quartile indicates the lower status and the $75^{\text {th }}$ reflects the highest. The obtained results suggested low and moderate, and moderate to high percentages for all dimensions and total score in the MMRC and MCNI groups, respectively. The Chi-square test results revealed a statistical significant difference between the two groups in all comparisons.

\section{Discussion}

The current study aimed to evaluate the health-related QoL in mothers of children with ID and compare it with mothers of healthy children in Shahr-e-kord, Iran. Interquartile range was used to evaluate the level of QoL among mothers. The results indicated that, the QoL in $46.8 \%$ of mothers of children with ID was low. While $96.5 \%$ of mothers of healthy children described their QoL as moderate and high and only 3.5\% of them had a poor QoL. This finding is consistent with the results of other studies $[26,27,32]$. 
Table 2. One-way ANOVA results of comparing QoL among the 4 groups of mothers

\begin{tabular}{|c|c|c|c|c|c|}
\hline \multicolumn{2}{|c|}{ Groups } & \multirow{2}{*}{$\begin{array}{l}\text { Mean } \\
59.85\end{array}$} & \multirow{2}{*}{$\begin{array}{c}\text { SD } \\
17.05\end{array}$} & \multirow[t]{2}{*}{ F, Eta-Squared } & \multirow{2}{*}{$\begin{array}{c}\text { Tukey's Test } \\
\text { D }\end{array}$} \\
\hline \multirow{5}{*}{ Physical functioning } & Educable (A) & & & & \\
\hline & Trainable (B) & 53.30 & 15.60 & \multirow{4}{*}{$51.18 *, 35.9 \%$} & $\mathrm{D}$ \\
\hline & & & & & \\
\hline & Isolated (C) & 59.18 & 16.86 & & D \\
\hline & Normal (D) & 80.27 & 14.54 & & $A, B, C$ \\
\hline \multirow{4}{*}{$\begin{array}{l}\text { Role limitations due to } \\
\text { physical health }\end{array}$} & Educable (A) & 43.35 & 15.36 & \multirow{4}{*}{$63.88^{*}, 40.7 \%$} & D \\
\hline & Trainable (B) & 38.74 & 13.97 & & D \\
\hline & Isolated (C) & 42.94 & 16.07 & & D \\
\hline & Normal (D) & 63.28 & 10.94 & & $A, B, C$ \\
\hline \multirow{4}{*}{$\begin{array}{l}\text { Role limitations due to } \\
\text { emotional problems }\end{array}$} & Educable (A) & 42.50 & 17.92 & \multirow{4}{*}{$40.05^{*}, 30.9 \%$} & D \\
\hline & Trainable (B) & 42.12 & 14.88 & & D \\
\hline & Isolated (C) & 41.72 & 18.18 & & D \\
\hline & Normal (D) & 62.03 & 12.63 & & $A, B, C$ \\
\hline \multirow{5}{*}{ Energy/fatigue } & Educable (A) & 43.75 & 12.85 & \multirow{5}{*}{$46.77 *, 34 \%$} & D \\
\hline & Trainable (B) & 42.50 & 10.14 & & D \\
\hline & & & & & \\
\hline & Isolated (C) & 45.55 & 13.34 & & D \\
\hline & Normal (D) & 59 & 9.14 & & $A, B, C$ \\
\hline
\end{tabular}

${ }^{*} \mathrm{P}<0.001$

IIranian Rehabilitation Journal

Assessing the dimensions of QoL in the current study revealed a significant difference between the QoL of mothers of children with ID and mothers of healthy children. In addition, the QoL of mothers of healthy children was higher in all 8 dimensions. This result is in line with the findings of Mubaraki and Bagheri [33], Malekshahi et al. [6] and Haqh-Ranjbar et al. [34] who examined the QoL of mothers of children with ID. Findings of this study are also consistent with the studies that examined the QoL of mothers of disabled children in general term $[5,13,25,26,35]$. The greatest difference between the 2 groups related to the dimension of physical role $(40.7 \%)$. This data suggests that, mothers of disabled children were facing more physical limitations in their role.

The slightest difference between the 2 groups related to the dimension of emotional role (30.9\%). This finding means that although mothers with disabled children are facing more limitations in their emotional role than those of healthy children, the two groups have the least differences in this dimension of QoL compared to other dimensions.
The QoL in all 3 groups of mothers of children with ID was not at a good level. However, the QoL of mothers of educable children was lower than that of mothers of trainable and isolated children. However, there were no significant differences among three groups of mothers in terms of dimensions of QoL and overall score. Such data indicated no significant difference between the severity of ID of children and QoL of mothers. These findings are inconsistent with the studies by Maleshahi and Fallahi [6], Amiri-Majd et al. [36], Ahmadi et al. [13], and Fadakar sogheh et al. [24]. This discrepancy is probably due to controlling other underlying and social variables in those studies. In the current study, before controlling and modifying the score of other variables, a significant difference was also found between the severity of disability and QoL.

Limitations of this research include selecting mothers of children with ID by convenience sampling method. Furthermore, the used tool in this study was designed for measuring QoL in the general population. However, the mothers of children with ID might have had condi- 
Table 3. One-way ANOVA results of comparing QoL among the 4 groups of mothers

\begin{tabular}{|c|c|c|c|c|c|}
\hline Factors & Groups & Mean & SD & F, Eta-Squared & Tukey's Test \\
\hline \multirow{5}{*}{ Emotional well-being } & Educable (A) & 51.92 & 10.91 & & D \\
\hline & Trainable (B) & 49.51 & 8.93 & & $D$ \\
\hline & & & & $50.79 *, 36.6$ & \\
\hline & Isolated (C) & 53.50 & 11.51 & & D \\
\hline & Normal (D) & 65.59 & 8.07 & & $A, B, C$ \\
\hline \multirow{5}{*}{ Social functioning } & Educable (A) & 51 & 13.01 & & $\mathrm{D}$ \\
\hline & Trainable (B) & 48.85 & 10.84 & & D \\
\hline & & & & $50.79 *, 35.7$ & \\
\hline & Isolated (C) & 51.20 & 13.24 & & D \\
\hline & Normal (D) & 66.86 & 9.26 & & $A, B, C$ \\
\hline \multirow{5}{*}{ Bodily pain } & Educable (A) & 51.78 & 14.65 & & D \\
\hline & Trainable (B) & 47.63 & 13.47 & & D \\
\hline & & & & $54.10^{*}, 37.5$ & \\
\hline & Isolated (C) & 51.70 & 15.41 & & D \\
\hline & Normal (D) & 70.73 & 11.92 & & $A, B, C$ \\
\hline \multirow{5}{*}{ General health } & Educable (A) & 40.46 & 13.83 & & D \\
\hline & Trainable (B) & 37.73 & 12.60 & & D \\
\hline & & & & $56.42^{*}, 37.6$ & \\
\hline & Isolated (C) & 39.90 & 13.94 & & D \\
\hline & Normal (D) & 57.50 & 9.87 & & $A, B, C$ \\
\hline \multirow{5}{*}{ QoL/total score } & Educable (A) & 49.34 & 14.26 & & D \\
\hline & Trainable (B) & 46.09 & 12.68 & & D \\
\hline & & & & $56.88^{*}, 37.6$ & \\
\hline & Isolated (C) & 48.78 & 14.66 & & D \\
\hline & Normal (D) & 67.15 & 10.79 & & $A, B, C$ \\
\hline
\end{tabular}

$* \mathrm{P}<0.001$

IIranian Rehabilitation Journal 
Table 4. Frequency distribution of the QoL in the two groups of mothers

\begin{tabular}{|c|c|c|c|c|c|}
\hline \multirow{2}{*}{ Dimension } & \multirow{2}{*}{ Group } & \multicolumn{3}{|c|}{ QoL Status (\%) } & \multirow{2}{*}{$\begin{array}{c}\text { Chi-Squared } \\
\text { Test }\end{array}$} \\
\hline & & High & Moderate & Low & \\
\hline \multirow{3}{*}{ Physical functioning } & MMRC & 9.5 & 44.5 & 46 & \\
\hline & & & & & $78.33^{*}$ \\
\hline & $\mathrm{MCNI}$ & 40.3 & 56.1 & 3.6 & \\
\hline \multirow{3}{*}{ Role limitations due to physical health } & MMRC & 8.6 & 45.7 & 45.7 & \\
\hline & & & & & $85.25^{*}$ \\
\hline & $\mathrm{MCNI}$ & 42.1 & 55 & 2.9 & \\
\hline \multirow{3}{*}{ Role limitations due to emotional problems } & MMRC & 7.3 & 46 & 46.7 & \\
\hline & & & & & $75.55^{*}$ \\
\hline & $\mathrm{MCNI}$ & 36.7 & 58.3 & 5 & \\
\hline \multirow{3}{*}{ Energy/fatigue } & MMRC & 10.1 & 44.9 & 44.9 & \\
\hline & & & & & $73.21 *$ \\
\hline & $\mathrm{MCNI}$ & 40.3 & 56 & 3.7 & \\
\hline \multirow{3}{*}{ Emotional well-being } & MMRC & 10 & 44.3 & 45.7 & \\
\hline & & & & & $75.33^{*}$ \\
\hline & $\mathrm{MCNI}$ & 40 & 56.3 & 3.7 & \\
\hline \multirow{3}{*}{ Social functioning } & MMRC & 9.4 & 44.6 & 46 & \\
\hline & & & & & $78.86^{*}$ \\
\hline & $\mathrm{MCNI}$ & 40.6 & 55.8 & 3.6 & \\
\hline \multirow{3}{*}{ Bodily pain } & MMRC & 8.5 & 46.1 & 45.4 & \\
\hline & & & & & $81.56^{*}$ \\
\hline & $\mathrm{MCNI}$ & 42.6 & 54.5 & 3 & \\
\hline \multirow{3}{*}{ General health } & MMRC & 9.8 & 44.1 & 46.2 & \\
\hline & & & & & 79.38* \\
\hline & $\mathrm{MCNI}$ & 40 & 56.4 & 3.6 & \\
\hline \multirow{3}{*}{ QoL/total score } & MMRC & 9.2 & 44 & 46.8 & \\
\hline & & & & & $84.05 *$ \\
\hline & $\mathrm{MCNI}$ & 41 & 55.6 & 3.5 & \\
\hline
\end{tabular}

IIranian Rehabilitation Journal

${ }^{*} \mathrm{P}<0.001$

Abbreviations: MMRC: Mothers of Mentally Retarded Children; MCNI: Mothers of Children with Normal Intelligence

tions affecting their QoL, which have not been included in SF-36. Furthermore, some personality traits of the mothers might have affected their QoL which were overlooked in this study.

\section{Conclusion}

Considering the above limitations, it can still be concluded that the QoL of mothers of children with ID and mothers of healthy children are completely different. Mothers of children with ID have lower self-esteem and lower functional level, due to physical problems, anxiety, stress, and depression caused by having a disabled child. Therefore, they have lower QoL. Only few studies reported contradictory results which can be contributed to the socio-cultural conditions of the studied communities. Findings of this study suggested that the mothers of children with ID (as members of the so- 
cial rehabilitation team) are affected by their children's care burden and this influences their QoL.

Mothers are important in the provision of rehabilitation services (secondary or tertiary prevention) to their children. Once their role in the rehabilitation team is ignored, not only the secondary and tertiary prevention activities for the disabled child will not be effective, but mothers may also become a primary recipient of rehabilitation services and among the vulnerable groups in near future. Therefore, during the provision of secondary and tertiary prevention services to children, mothers as the primary caregivers to children should be monitored with the aim of primary prevention.

\section{Ethical Considerations}

\section{Compliance with ethical guidelines}

Prior to study, all participants signed a written informed consent, approved by the Ethics Committee of the University of Social Welfare and Rehabilitation Sciences.

\section{Funding}

This study was supported by grant No. 14144 of the University of Social Welfare and Rehabilitation Sciences.

\section{Authors contributions}

The authors contributions is as follows: Conceptualization, investigation, writing original draft, writingreview and editing: All authors; and methodology and analysis: Gholamreza Ghaedamini Harouni.

\section{Conflict of interest}

The authors declared no conflict of interest.

\section{Acknowledgements}

The authors very much appreciate the support by all those who collaborated on this research, especially the Social Welfare Management Research Center. We also gratefully acknowledge the financial support of ViceChancellor of Research and Technology Department of University of Social Welfare and Rehabilitation Sciences.

\section{References}

[1] Mirkhani SM. [Principles of rehabihhtation (Persian)]. Tehran University of Social Welfare and Rehabilitation Sciences; 2011.

[2] World Health Organization. World report on disability. Geneva: World Health Organization; 2011.

[3] Mugno D, Ruta L, D’Arrigo VG, Mazzone L. Impairment of quality of life in parents of children and adolescents with pervasive developmental disorder. Health and Quality of Life Outcomes. 2007; 5(1):22. [DOI:10.1186/1477-7525-5-22]

[4] Taghizadeh H, Asadi R. [Comparative analysis of quality of life in mothers of children with mental disability and mothers of normal children (Persian)]. Journal of Rehabilitation Sciences. 2015; 4(8):66-74.

[5] Fairthorne J, Jacoby P, Bourke J, de Klerk N, Leonard H. Onset of maternal psychiatric disorders after the birth of a child with intellectual disability: A retrospective cohort study. Journal of Psychiatric Research. 2015; 61:223-30. [DOI:10.1016/j. jpsychires.2014.11.011]

[6] Malekshahi F, Falahi S. [Psychosocial problems of parents of mentally disabled children covered by Khorramabad Welfare Center (Persian)]. Lorestan University of Medical Sciences. 2017; 18(3):42-51

[7] Davarmanesh A. Mentally retarded children education \& rehabilitation. Tehran: University of Social Welfare and Rehabilitation Sciences; 2011. [PMID]

[8] Dadkhah A, Ghaffar Tabrizi R, HemmatiS. [Quality of life of disabled children's mother: A comparative study (Persian)]. Iranian Rehabilitation Journal. 2009; 7(2):36-7.

[9] Brown RI, MacAdam Crisp J, Wang M, Iarocci G. Family quality of life when there is a child with a developmental disability. Journal of Policy and Practice in Intellectual Disabilities. 2006; 3(4):238-45. [DOI:10.1111/j.1741-1130.2006.00085.x]

[10] Mohaqeqi Kamal SH, Basakha M, Ghaedamini Harouni G. Women's well-being in Iran: Territorial analysis using a multidimensional approach. Social Indicators Research. 2018; 137(3):1061-72. [DOI:10.1007/s11205-017-1656-7]

[11] Mooney A. Quality of life: Questionnaires and questions. Journal of Health Communication. 2006; 11(3):327-41. [DOI:10.1080/10810730600614094]

[12] Felce D, Perry J. Quality of life: The scope of the term and its breadth of measurement. In: Brown RI, editor. Quality of Life for People With Disabilities: Models, Research and Practice. Cheltenham: Stanley Thornes; 1997.

[13] Ahmadi K, Khodadadi G, Anisi J, Abdolmohammadi E. Problems of families with disabled children. Journal of Military Medicine. 2011; 13(1):49-52.

[14] Schieve LA, Blumberg SJ, Rice C, Visser SN, Boyle C. The relationship between autism and parenting stress. Pediatrics. 2007; 119(Suppl. 1):S114-S21. [DOI:10.1542/ peds.2006-2089Q]

[15] Chu J, Richdale AL. Sleep quality and psychological wellbeing in mothers of children with developmental disabilities. Research in Developmental Disabilities. 2009; 30(6):1512-22. [DOI:10.1016/j.ridd.2009.07.007]

[16] Davis E, Shelly A, Waters E, Boyd R, Cook K, Davern M. The impact of caring for a child with cerebral palsy: 
Quality of life for mothers and fathers. Child: Care, Health and Development. 2010; 36(1):63-73. [DOI:10.1111/j.13652214.2009.00989.x]

[17] Leung CYS, Li Tsang CWP. Quality of life of parents who have children with disabilities. Hong Kong Journal of Occupational Therapy. 2003; 13(1):19-24. [DOI:10.1016/S1569 1861(09)70019-1]

[18] Moore A, Kornblet S. Advancing the rights of persons with disabilities: A US-Iran dialogue on law, policy, and advocacy. Bergen County: Blue Law; 2011.

[19] Cadman D, Rosenbaum P, Boyle M, Offord DR. Children with chronic illness: Family and parent demographic characteristics and psychosocial adjustment. Pediatrics. 1991; 87(6):884-9. [PMID]

[20] Emerson E, Hatton C, Llewellyn G, Blacker J, Graham H. Socio-economic position, household composition, health status and indicators of the well-being of mothers of children with and without intellectual disabilities. Journal of Intellectual Disability Research. 2006; 50(12):862-73. [DOI:10.1111/ j.1365-2788.2006.00900.x]

[21] Lin JD, Hu J, Yen CF, Hsu SW, Lin LP, Loh CH, et al. Quality of life in caregivers of children and adolescents with intellectual disabilities: Use of WHOQOL-BREF survey. Research in Developmental Disabilities. 2009; 30(6):1448-58. [DOI:10.1016/j.ridd.2009.07.005]

[22] Payot A, Barrington KJ. The quality of life of young children and infants with chronic medical problems: Review of the literature. Current Problems in Pediatric and Adolescent Health Care. 2011; 41(4):91-101. [DOI:10.1016/j.cppeds.2010.10.008]

[23] Romeo D, Cioni M, Distefano A, Battaglia L, Costanzo L, Ricci D, et al. Quality of life in parents of children with cerebral palsy: Is it influenced by the child's behaviour? Neuropediatrics. 2010; 41(03):121-6. [DOI:10.1055/s-0030-1262841]

[24] Fadakar Sogheh R, Abbasi S, Khaleghdoost T, Atrkar Roshan Z. [Family's mentally retarded child problems under protection of welfare centers (Persian)]. Journal of Holistic Nursing and Midwifery. 2014; 24(3):38-47.

[25] Abasi S, Fadakar K, Khaleghdoost T, Sedighi A, Atrkar Roshan Z. [Survey the problems of families with mentally retarded child covered by Guilan Welfare Centers in 2010 (Persian)]. Journal of Holistic Nursing and Midwifery. 2010; 20(1):33-9.

[26] Khanjari S, Oskouie F, Eshaghian Dorche A, Haghani $\mathrm{H}$. [Quality of life in parent of children with leukemia and its related factors (Persian)]. Iran Journal of Nursing. 2013; 26(82):1-10.

[27] Sajjadi H, Vameghi M, Ghazinour M, Khodaei Ardakani M. Caregivers' quality of life and quality of services for children with cancer: A review from Iran. Global Journal of Health Science. 2013; 5(3):173-82. [DOI:10.5539/gjhs.v5n3p173]

[28] Zandi H. [The relationship between coping strategies and mental health in parents of educable mental retardation and normal children in Sanandaj (Persian)]. Tehran: University of Social Welfare and Rehabilitation Sciences; 2006.

[29] Colver A. Measuring quality of life in studies of disabled children. Paediatrics and Child Health. 2008; 18(9):423-6. [DOI:10.1016/j.paed.2008.05.011]
[30] Karimi Dermani HR. [Rehabilitation specific groups emphasized on social work services (Persian)]. Tehran: Roshd; 2011.

[31] Montazeri A, Goshtasebi A, Vahdaninia M, Gandek B. The short form health survey (SF-36): Translation and validation study of the Iranian version. Quality of Life Research. 2005; 14(3):875-82. [DOI:10.1007/s11136-004-1014-5]

[32] Montazeri A, Gashtasbi A, Vahdani Niya MS. [Translation, validity and reliabity of percian version of SF-36 (Persian)] Payesh. 2005; 5(1):49-56.

[33] Mobaraki A, zadeh Bagheri G. [Comparison of knowledge and attitude of mothers with mentally retarded children with those without mentally retarded children in Gachsaran (Persian)]. Armaghan-e Danesh. 2003; 8(21):81-90.

[34] Haqranjbar F, Kakavand A, Borjali A, Bermas H. [Resiliency and quality of life among mothers of disabled child (Persian)]. Quarterly Journal of Health Psychology. 2012; 1(1):177-87.

[35] Rahimi S, Fadakar Soghe R, Tabri R. [Related factors with quality of life among preschool children with cancer (Persian)]. Journal of Holistic Nursing and Midwifery. 2014; 24(1):30-9.

[36] Amiri Majd M, Laya Q. [Comparison of quality of life and behavioral disorders in children with Down syndrome, pediatric and normal children (Persian)]. Behavioral Sciences. 2010; 2(6):21-38. 
This Page Intentionally Left Blank 